"Сучасні технології та методи розрахунків у будівництві", випуск 11, 2019

УДК 7.025.4

DOI: 10.36910/6775-2410-6208-2019-1(11)-19

\title{
ПРОБЛЕМЫ ВОССТАНОВЛЕНИЯ ЛЕПНЫХ УКРАШЕНИЙ ПРИ АРХИТЕКТУРНОЙ И ИНЖЕНЕРНОЙ РЕСТАВРАЦИИ ПАМЯТНИКОВ Г. ОДЕССЫ
}

\section{ПРОБЛЕМИ ВІДНОВЛЕННЯ ЛІПНИХ ПРИКРАС ПРИ АРХІТЕКТУРНІЙ ТА ІНЖЕНЕРНІЙ РЕСТАВРАЦЇ̈ ПАМ'ЯТОК М.ОДЕСИ}

\section{PROBLEMS OF STUCCO MOULDING'S RENOVATION DURING THE ARCHITECTURAL AND ENGINEERING RESTORATION OF ODESA'S MONUMENTS}

Чернева Е.С., к.т.н., доцент, Плахотный Г.Н., к.т.н., доцент, Черненко А.А., преподаватель (Одесская государственная академия строительства и архитектуры)

Чернсва О.С., к.т.н., доцент, Плахотний Г.Н., к.т.н., доцент, Черненко А.А., викладач (Одеська державна академія будівництва та архітектури)

Chernieva O.S., Ph.D. in Engineering, Associate Professor, Plahotny H.N., Ph.D. in Engineering, Associate Professor, Chernenko A.A. (The Odessa State Academy of Building \& Architecture)

В статье изложены основные принципы и требования к восстановлению лепных украшений при реставрационностроительных работах. Анализируется состояние лепных украшений зданий - памятников архитектуры и методов их временного укрепления.

У статті викладені основні принципи і вимоги до відновлення ліпних прикрас при реставраційно-будівельних роботах. Аналізується стан ліпних прикрас будівель - пам'яток архітектури та методів їх тимчасового зміцнення.

Причинами зносу елементів ліпнини в пам'ятках архітектури Одеси $\epsilon$ низка факторів: некоректність експлуатації будівлі, діяльність людини; військові злочини; нехтування фактичним розподілом напружень в окремих елементах; вплив атмосферних 
опадів; нерівномірне зволоження грунтів основи, яке викликає осадку фундаментів; вплив рельєфу місцевості, інсоляція; сейсмічні впливи, вібрація від руху поїздів та автотранспорту; корозія металевих кріплень, втрата несучої здатності в'язів; зміна конструктивної схеми споруди, викликана прибудовами.

Процес старіння пам'ятника може бути сповільнено або призупинено шляхом проведення реставраційних робіт. Основне завдання реставрації - на базі наукових досліджень, вивчення історичних даних розробити проектні інженерно-технічні рішення, що визначають його долю в майбутньому.

Першочергова задача реставраторів - демонтаж аварійних елементів. Необхідно пам'ятати, що це може врятувати життя. При цьому не можна забувати, що декоративний елемент - це прикраса будинку, його деталь. I «лікування» «каріатиди» неможливо без «лікування» всієї будівлі.

The article is devoted to problems of the Odessa historical center. Architectural monuments of Odessa are known all over the world and cause a keen interest among tourists. Restoration of the architectural and historical appearance of Odessa is one of the promising areas of the city development. However, the processes of wear and aging of monuments are inevitable, and they did not spare the moldings of the facades and the interior, which convey the features of the architectural style of the building and immerse us in the era of that time.

The main causes of stucco wear include: incorrect use of the building; war crimes; impact from seismic effects and vibration from passing vehicles; solar radiation; temperature fluctuations; air flow; precipitation; chemical substances; thunderstorms, sound vibrations; biological pests.

Relief moldings - ornamental, structural and figured - on the facades, in the interiors of architectural monuments are often made by casting from plaster, and can also be wrung out from lightweight concrete and other mixtures. Restoration of architectural stucco decoration is a complex of works.

The first stage is a detailed study of the original stucco samples and cleaning of moldings from the layers of paint.

The second stage is repair of molded products. In a detailed study of a stucco sample, special attention is paid to its strength. Weak, fragile fragments that crumble - remove. At the same time, a satisfactory 
appearance of these products is not an indicator of good condition, since the destruction may be hidden and not determined visually. When cleaning from layers, the old paint layer is removed not to the white color of the plaster, but to the dark layer of drying oil. In case the gypsum is not saturated with linseed oil, but painted, it is enough to remove the layering of paint to the original layer of paint. Oil coatings are more resistant and can be removed chemically. Restoration of moldings is made up of four production processes: the execution of a full-size model; making a casting form from this model, casting the architectural part itself and installing it in the place provided for by the restoration project.

Stucco molding is attached to the wall with brass or stainless steel rods or fiberglass, installed in the drilled holes, fixed thickened mass of gypsum. After fixing the gypsum fragment, its surface should be treated with a $30 \%$ solution of ferrous or copper vitriol, then with a $10 \%$ solution of barium sulfate, which ensures the strength of the gypsum part.

Conclusions: unfortunately, the stucco condition of most of the architectural monuments of Odessa is unsatisfactory, and in some places it is in danger of collapse. A promising direction of development of the city is the speedy restoration of the original appearance of buildings and stucco decorations as well.

Ключевые слова: Реставрация, консервация, лепнина, модель, форма, баста, гипс.

Ключові слова: Реставрація, консервація, ліпнина, модель, форма, баста, гіпс.

Keywords: Restoration, conservation, stucco decoration, model, mould, basta, gypsum.

Одессу в начале 19-го века называли «скороспелкой». Действительно, город стремительно развивался. Первоначально предначертанное назначение быть военной базой очень скоро потеряло свою актуальность. Военные действия были перенесены из этого региона, и из военного город становился торговым. Герои войны с турками, а позднее с французами находили здесь желанный мир и покой. Впрочем, герои на войне, они не могли оставаться в праздности и продолжали бурную деятельность на гражданском поприще. Так первыми руководителями города, инженерами, 
строителями были люди военные. Умелое управление вывело город в ряд ведущих городов империи. Он был привлекательным для инвестиций, для эмигрантов всех сословий, для уроженцев соседних и дальних держав. Одессе не нужны были века для того чтобы взрастить свою культуру. Мультикультура стала особенностью «Южной Пальмиры», она и породила свой стиль, со временем только обогащаемый новыми веяниями архитектурной моды и инженерных технологий. Типовой ампир жилых и общественных зданий в начале века девятнадцатого к его концу был на 70\% замещён эклектикой и модерном доходных домов. И, конечно, не маловажную роль в неповторимости и качестве южного стиля сыграл декор этих зданий. Своим неповторимым великолепием, красотой пластики лепнина одесских зданий в первую очередь обязана, конечно, итальянским мастерам, благодаря которым мы сегодня любуемся прекрасными скульптурами, украшающими балконы, фасады, фронтоны [1].

Одно из первых упоминаний об итальянских скульпторах в Одессе можно найти в архиве в Фонде Строительного комитета от 1820 года, из документа видно, что в 1805 году скульптор Карл Боргио обязался по контракту «сделать в католической церкви столбовые капители». Уже в первой половине позапрошлого века итальянские мастера по изготовлению памятников, каминов, парковых скульптур заняли в Одессе монопольное положение, которое сохраняли до конца столетия. Причисляя свой цех к «ремесленной аристократии», или к «художественной братии», они селились со своими «ателье» в центре города.

Бриллиант в короне Одессы - Театр оперы и балета, Городской театр, проект был выполнен венским архитектурным бюро «Фельнер Ф. и Гельмер Г.» в 1880г. Надо отметить, что архитектурное бюро «Фельнер Ф. и Гельмер Г.» предоставляло не только проекты, в его состав входили и скульпторы, и декораторы. Известны имена мастеров, которые выполняли скульптуры оперного театра от бюро: Этель Ф., Стрикциус Л., Фридль Ф. А монтажом и скульптурными работами непосредственно на строительной площадке занимались одесские скульпторы: Натали Ф. А., Молинари М. Л., $1884-1887$ гг. К слову сказать: сегодня многие сетуют, что, дескать, оригинальная скульптура с оперного театра валяется и разрушается в сараях. Однако эта скульптура была изначально обречена. Дело в том, что австрийские мастера 
совершенно не учли особенности морского климата и в силу этого достаточно агрессивной окружающей среды, и использовали в своих скульптурах обычную железную арматуру. Коррозируя стальные прутья, увеличивались в диаметре и просто разрывали статуи изнутри (рис.1) [2].

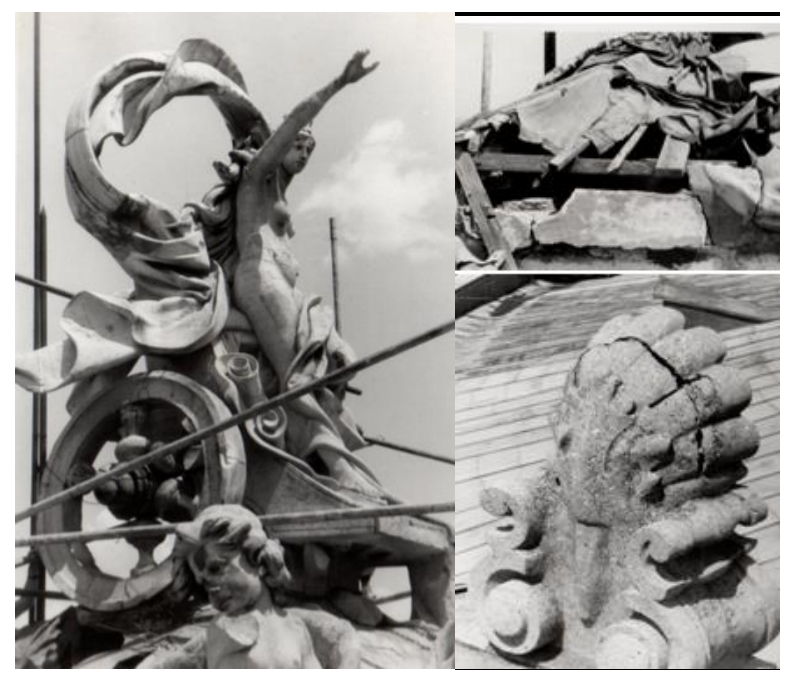

Рис. 1. Состояние скульптур Театра Оперы и балета 1992г.

Но вернёмся к одесским скульпторам. Здесь творили не только итальянцы. Ближе к концу века на творческом небосклоне засияли две звезды, представители еврейского народа.

Одесский Пассаж. Это один из первых в Российской империи торговых центров. Его заказал купец Моисей Менделевич. Здание построено в 1899г. и весь его внешний вид был задуман, как демонстрация роскоши и удачи. Именно поэтому, на стенах Пассажа преобладают скульптуры богини удачи, Фортуны и бога торговли - Меркурия. В руках Фортуны, неизменный факел удачи, а Меркурий всегда изображается с жезлом и мешочком денег. На фото (рис.2) - внутренняя часть входа в Пассаж, который не претерпел никаких изменений. 


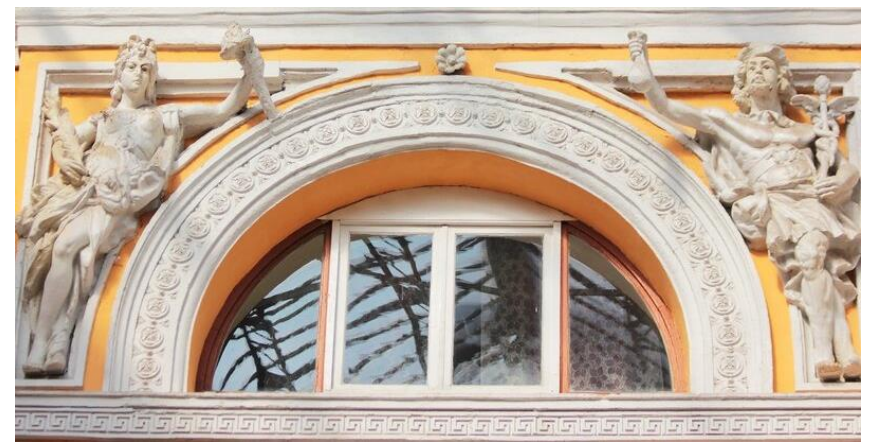

Рис.2. Внутренняя часть входа в Пассаж

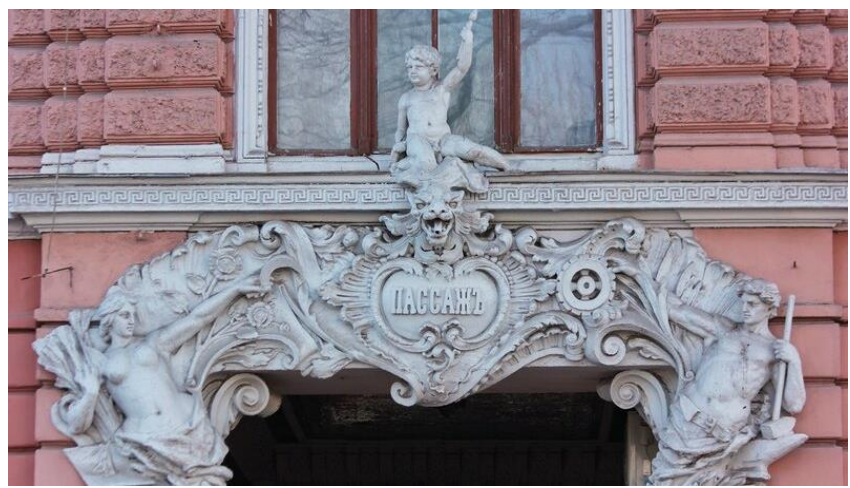

Рис.3. Внешняя часть арки Пассажа со стороны Дерибасовской

А на рис.3 фото внешней части арки Пассажа со стороны Дерибасовской. Тут тоже изображены Фортуна и Меркурий, но к ним в советское время приложились руки патриотичного скульптора (Фортуна приобрела серп, Меркурий молот и рабочий пояс).

Много прекрасных архитекторов и скульпторов работало над созданием удивительного декора прекрасных одесских зданий. Они создавали модель, формовали, отливали, монтировали свои произведения. Будь-то простой кронштейн, сухарик (денти́кул (от лат. denticulus - зубец), или «ордерные сухарики» - ряд небольших прямоугольных выступов, расположенных в виде орнамента на карнизе здания и выполняющих роль декора рис.4), или кариатида, всё это прошло через мысли и руки творца, художника, мастера и со временем пришло в негодность. 


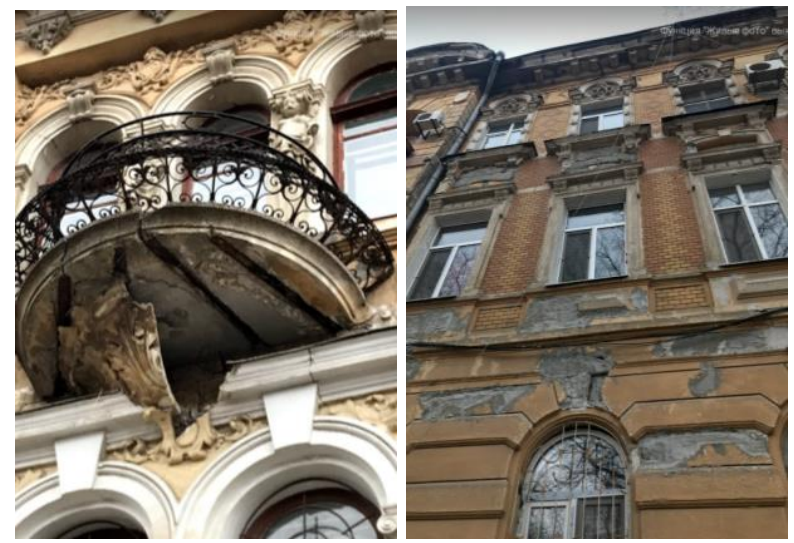

Рис. 4. Памятник архитектуры - Доходный дом Кефала, ул. Маразлиевская 44 и Маразлиевская 38. Разрушение лепнины

Причинами износа элементов лепнины в памятниках архитектуры являются: некорректность эксплуатации строения; деятельность человека; военные преступления; пренебрежение к фактическому распределению напряжений в отдельных элементах; влияние атмосферных осадков; неравномерное увлажнение грунтов основания, которое вызывает осадку фундаментов; воздействия от морозного пучения; влияние рельефа местности, инсоляция; влияние от сейсмических воздействий, вибрация от проходящих вблизи поездов, автотранспорта и т.д.; коррозия металлических креплений, потеря несущей способности связей; изменение конструктивной схемы сооружения, вызванное пристройками.

Процесс старения памятника может быть замедлен или приостановлен путем проведения реставрационных работ.

Реставрация - научно-производственный комплекс мероприятий, обеспечивающий воссоздание архитектурно художественного облика, а также восстановление первоначальной эксплуатационной надежности памятника на последующий период времени [3].

Целью реставрации является, основываясь на глубоком изучении архивных материалов и обследовании памятника в натуре, максимально сохранить, выявить и, по возможности, восстановить памятник в историческом, конструктивном и художественном отношении, обеспечить его долговечное существование. 
При этом также учитывается состояние подземных инженерных коммуникаций, транспортных потоков, загрязнение воздушных и водных бассейнов, что влияет на сохранность памятника.

Основная задача реставрации - на базе научных исследований, изучения исторических данных, разработать проектные инженернотехнические решения, определяющие его судьбу в будущем.

Предварительными работами при выполнении реставрации является консервация объекта.

Консервация - сохранение архитектурного стиля памятника, дошедшего до нашего времени с позднейшими историческими напластованиями.

Основные этапы консервации: расчистка, укрепление конструкций и материалов, укрытие его от влияния внешней среды.

Расчистка архитектурных элементов - вид исследований, не затрагивающий конструкций, а заключающийся в удаление поверхностного загрязнения для выявления цвета, фактуры памятников, послойная расчистка окрасок, выявление поверхностных наслоений штукатурки.

Не следует очищать фрески старыми щетками и тем более скребками без последующей шлифовки поверхности карборудным камнем.

Рельефные лепные украшения - орнаментальные, структурные и фигурные - на фасадах, в интерьерах памятников архитектуры чаще всего изготавливаются методом отливки из гипса, а также могут отжиматься из легких бетонов и прочих смесей. Реставрация архитектурного лепного декора - целый комплекс работ.

Первый этап - детальное изучение первоначальных лепных образцов и очистка лепных украшений от наслоений краски.

Второй этап - тщательный ремонт лепных изделий. При детальном исследовании лепного образца особое внимание обращается на его прочность. Слабые, непрочные фрагменты, которые крошатся - удаляют. При этом удовлетворительный внешний вид этих изделий не является показателем хорошего состояния, так как деструкция может быть скрытой и не определяется визуально. При очистке от наслоений, старый слой краски снимают не до белого цвета гипса, чтобы не повредить пропитанный олифой слой гипса, и не исказить первоначальной формы фрагментов, а до темного слоя олифы. В случае, если гипс не пропитан олифой, а покрашен, достаточно снять наслоения 
краски до первоначального слоя краски. Масляные покрытия более стойки и их можно снять химическим способом. Размягчить слой масляной краски можно также щелочной пастой (просеянный мел и известковое тесто, разведенные $20 \%$ составом каустической содой). После того через 1,0-1,5 часа слой краски удаляют шпателем. После очистки масляной краски поверхность промыть водой и $2 \%$ раствором уксусной кислоты. Остатки смывки удаляются, а образец протирают уайт - спиритом. При восполнении утрат гипсового декора, так называемая «гипсовка», на поврежденные участки наносится гипсовый раствор с добавлением известкового теста.

Детали лепки изготавливаются из гипса в следующей последовательности: изготовление шаблона; изготовление формы; отливка гипсовых деталей; догипсовка (по необходимости); проолифование; монтаж детали по фасаду.

Модель - выполнение в каком-либо материале воплощения внешней формы предмета. Модель выполняется по рисункам чертежам, шаблонам, фотографиям. С модели снимают форму.

Форма - точный рельеф (слепок) модели. Цель формовочных работ - получить форму для воспроизведения необходимого числа копий моделей. В лепном производстве распространены следующие виды форм: гипсовая (черновая), получистая и чистая (кусковка), эластичная (клеевая, комбинированная, цементная, бетонная, деревянная, металлическая.

Реставрация лепных изделий - детальное изучение орнаментов, освобождение лепнины от последующих покрасок, чтобы полностью сохранить первоначальный декор и четкость рельефных изображений. Техника реставрации лепнины требует большой тщательности исполнения.

Детали лепного декора подвергаются значительным разрушениям от влаги, естественного обветшания, технических повреждений. Наиболее распространенный вид искажений лепных деталей - изменение их профилировки и рельефов позднейшими многократными покрасками. После расчистки лепных деталей от краски видны картины их повреждений. Чаще всего это швы соединения их частей, выбоины, поломки, трещины и сколы. Прежде всего закрепляют детали или их части, которые могут обрушится. Для этого забивают дополнительные костыли, старые подбивают в стену, ржавую проволоку заменяют новой. Все швы и трещины расшивают для дальнейшего заполнения их гипсом. 
Размякший гипс вырезают, места обломов подготавливают для лепки на них утерянных частей. Для восстановления мелких недостающих деталей орнамента, места покрывают мелкой насечкой, затем разводят гипсовый раствор и, пока он еще жидкий, покрывают места, подлежащие реставрации.

Лепнину крепят к стене стержнями из латуни или из нержавеющей стали или стеклопластиков, устанавливаемых в просверленные отверстия, закрепленные загустевшей массой гипса.

После закрепления гипсового фрагмента его поверхность следует обработать $30 \%$ раствором железного или медного купороса, затем $10 \%$ раствором сульфата бария, что обеспечивает прочность гипсовой детали [4].

Следует уделить внимание также такому виду декоративноприкладного исскуства, как баста (тюрк. «тиснение»). Басту используют в тех случаях, когда необходимо получить множество одинаковых узоров для багетов, карнизов, рам. Особенность басты заключается в изготовлении по готовой модели матриц из бронзы или цинка. По матрице необходим пуансон из свинца с его обратным изображением (контррельефом). Басменный узор устраивается путем тиснения металлического листа между матрицей и пуансоном. Возможно многократное изготовление такого узора.

Выводы: после того, как декоративный элемент занял своё место на фасаде, над ним стало работать время. И вот сегодня, к несчастью, произведения искусства превращаются в просто камни. Опасные, тяжелые камни, опасные для жизни человека, для жизни горожанина. Первостепенная задача реставраторов - демонтаж аварийных элементов. Необходимо помнить, что это может спасти жизнь. При этом нельзя забывать, что декоративный элемент - это украшение здания, его деталь. И «лечение» «кариатиды» невозможно без «лечения» всего здания.

1. Асєєв Ю.С. Професія - архітектор. Київ: Видавництво «Будівельник», 1991. 102c. 2. Бондаренко Н.И. Одесский бестиарий. Зооморфные и мифологические символы в архитектуре и скульптуре Одессы. Одесса: ФЛП «Фридман А.С.», 2012. 56с. 3. Кедринский А.Н. Основы реставрации памятников архитектуры. М.: Изобразительное искусство, 1999. 184c. 4. Ивлиев А.А., Кальгин А.А. Реставрационные строительные работы. М.: Издательский центр «Академия», 2006. 272c. 